\title{
Impact of Breast Milk Secretory Immunoglobulin A on Infants Acute Gastroenteritis
}

\author{
Marija Dimitrovska-Ivanova ${ }^{1 *}$, Elizabeta Zisovska ${ }^{2}$ \\ ${ }^{1}$ Department of Pediatrics, Clinical Hospital - Shtip, Shtip, Republic of Macedonia; ${ }^{2}$ University Clinic for Gynecology and \\ Obstetrics, Skopje, Republic of Macedonia
}

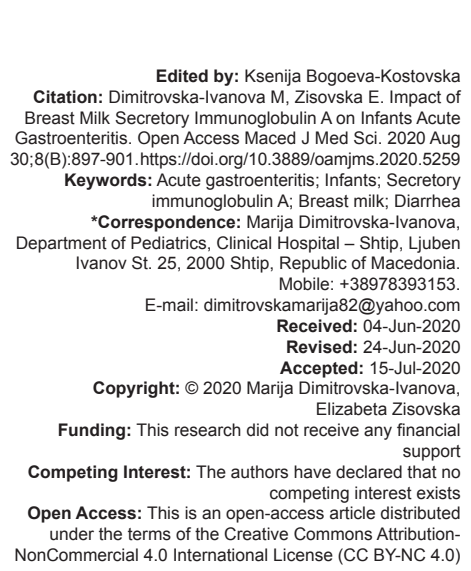

Introduction

Acute gastroenteritis is one of the most common infections in childhood ant it can be especially dangerous in the first 6 months of life with a higher risk of increased water and electrolyte loss with consequent moderate to severe dehydration, especially in infants who are not exclusively breastfed. The incidence of acute gastroenteritis ranges from 0.5 to 2 episodes per child per year in children younger than 3 years. At this age, acute gastroenteritis is the most common cause of hospitalization [1]. Acute gastroenteritis is defined as a decrease in stool consistency and/or an increase in the frequency of discharges ( $\geq 3$ in $24 \mathrm{~h}$ ) with or without fever and vomiting [1]. Rotavirus is the most common cause of acute gastroenteritis, rarer causes are Adenovirus, Norovirus, and Astrovirus. Bacterial pathogens include Salmonella, Shigella, and less commonly Escherichia coli, Campylobacterjejuni, and Yersinia enterocolitica. Enterocyte infection leads to cell death, lumen extrusion, and atrophy of the intestinal villi, resulting in reduced intestinal surface area, with impaired digestive and absorption functions and acute transient malabsorptive diarrhea.

The secretory immunoglobulin $A(\lg A)$ is the first line of defense for the intestinal epithelium from pathogenic microorganisms and intestinal toxins. It prevents the binding of microorganisms to epithelial receptors by binding it to the $\mathrm{Fc}$ receptor on the surface of the pathogen, trapping microorganisms in the mucus, and enabling their removal by stimulating peristalsis and mucociliary activity [2], [3]. slgA is able to directly reduce bacterial virulence and it has an effect on the composition of the intestinal microflora [2]. IgA is a weak activator of complement and it poorly opsonizes [2].

Breast milk is a link between the mother's immune system and the infant. Although infants have antibodies vertically transmitted from the mother (transplacental), they remain unprotected when they come in contact with new microorganisms [4]. slgA is the most important immunoglobulin in breast milk not only because of its high concentration but also because of its biological activity [5], [6]. Natural and specific slgA antibodies in breast milk are capable of binding to commensal bacteria and may be involved in establishing of the intestinal microflora of the newborn, which, in turn, stimulates the maturation of intestinal lymphatic tissue, resulting in the production of slgA with limited affinity of recognition and removal of pathogenic microorganisms [2]. A number of studies have confirmed that exclusive breastfeeding has a protective role and 
reduces the risk of diarrhea, especially in infants up to 6 months of age [7], [8].

The aim of this study was to assess whether slgA from breast milk has a protective effect on the intestinal epithelium by evaluating the severity and duration of the clinical signs in infants under 6 months with acute gastroenteritis depending on the type of nutrition.

\section{Materials and Methods}

\section{Study design}

This was a prospective cohort study started on November 15, 2018, and lasted until December 31,2019 . The study included newborns and infants from birth to 6 months of age who were diagnosed with acute gastroenteritis. All infants were hospitalized at the Children's Department in Clinical Hospital - Shtip. Parents' written consent was obtained for each infant included in the study after extensive communication with them. An appropriate survey questionnaire was designed and responses were obtained from the infants' mothers. The questionnaire covered the following segments: Infant age, nutrition (breast milk, milk formula, or cow's milk), and weaning practice. Information on the onset of symptoms of acute gastroenteritis in the past $24 \mathrm{~h}$ before admission, as well as information on the diet and health status of the nursing mother were included. Infants were divided into two groups according to age in months and according to milk nutrition and introduction of complementary food.

Group I included newborns and infants from birth to 6 months who were exclusively breastfed. Group II included newborns and infants from birth to 6 months of age who were not exclusively breastfed and were on mixed milk nutrition.

Exclusively breastfed were infants who were fed only with breast milk and did not receive additional food or fluids (excluding oral rehydration solution, vitamins, minerals, and medications). The clinical picture and degree of dehydration were determined by physical examination and the degree of dehydration was divided into mild, moderate, and severe through the use of a clinical scoring system. (World Health Organization: Integrated management of childhood illness-Module 4, Diarrhea). For each infant included in the study, a record sheet was filled and according to the severity of the clinical signs, the need for parenteral rehydration was assessed during the hospital stay. The study did not include infants whose diarrhea was due to a surgical or extra-intestinal cause, as well as infants who had received immunosuppressive therapy.

\section{Laboratory methods}

From each infant included in the study, two samples of diaper stool were taken with a plastic spatula.
One sample stool was collected in a sterile plastic cup with the general data of the patient and the code written on it and within $30 \mathrm{~min}$, it was taken to the Microbiological Laboratory in the Center for Public Health (CPH) - Shtip. In this stool sample, it was proved the presence of Rotavirus and Adenovirus with immunochromatographic test (DUO ROTA-ADENOVIRUS - Check-1 VEDA. $\mathrm{LAB}$, Alencon-France). From the same stool sample, a coproculture was performed which disproved the presence of enteropathogenic bacteria by sowing the stool sample on a suitable substrate. The second stool was frozen at $-80^{\circ} \mathrm{C}$ and in that sample, the slgA level was determined quantitatively by ELISA method with ELISA kit test by Immundiagnostik, Bensheim, Germany.

\section{Statistical analysis}

The collected data were processed using the statistical program SPSS 20 and the following statistical methods: Attributive statistical series were analyzed by determining percentages. Numerical series were analyzed with central tendency measures and with data dispersion measures. Statistical significance of the probability between numerical series was determined using Student's t-test. The odds ratio-OR cross-correlation is used to determine the relationship between the dependentcriterion variable and the independent. With Shapiro-Wilk test, the normality of variable distribution was tested. For confidence interval $(\mathrm{Cl})(95 \% \mathrm{Cl})$, statistical significance was defined at the level of standard error $<0.05$ (p). The results are shown in tables and figures.

\section{Results}

The analysis included 23 hospitalized infants from birth to 6 months of age with a diagnosis of acute gastroenteritis, divided into two groups. The first group included 7 (30.4\%) infants and the second group included $16(69.6 \%)$ infants, divided by age expressed in months and type of nutrition.

Table 1 presents the infants with acute gastroenteritis by gender and sex.

Table 1: Distribution of the infants according to the gender and age

\begin{tabular}{|c|c|c|c|c|}
\hline Group & 1 & & II & \\
\hline Gender & Number & $\%$ & Number & $\%$ \\
\hline Male & 4 & 57.1 & 9 & 56.25 \\
\hline Female & 3 & 42.9 & 7 & 43.75 \\
\hline Age in months & Number & Mean! SD & Number & Mean! SD \\
\hline & 7 & $2.1 ! 0.899735$ & 16 & $3.4 ! 1.454877$ \\
\hline
\end{tabular}

The average infant age in the first group was $2.1 \pm 0.9$ months and in the second group was $3.4 \pm 1.5$ months.

The distribution of the clinical signs in both groups is presented in Table 2, which included the average number of vomiting, average number of liquid 
Table 2: Clinical condition $24 \mathrm{~h}$ before admission and during the hospitalization

\begin{tabular}{|c|c|c|c|c|c|c|c|c|}
\hline Group & Average I & Average II & t-test & $\mathrm{p}$ & $\mathrm{NI}$ & $\mathrm{N} \mathrm{II}$ & SD I & SD II \\
\hline Number of vomiting $24 \mathrm{~h}$ before admission & 0.285714 & 4.56250 & -3.40460 & 0.002669 & 7 & 16 & 0.487950 & 3.265348 \\
\hline Number of stools $24 \mathrm{~h}$ before admission & 3.7 & 10.4 & -3.49610 & 0.002152 & 7 & 16 & 0.755929 & 4.951431 \\
\hline Number of stools during the hospitalization & 9.0 & 21.2 & -3.67211 & 0.001419 & 7 & 16 & 2.236068 & 8.549610 \\
\hline Number of vomiting during the hospitalization & 0.3 & 3.0 & -2.90250 & 0.008516 & 7 & 16 & 0.755929 & 2.394438 \\
\hline Number of parenteral rehydration days & 0.7 & 2.0 & -3.11436 & 0.005246 & 7 & 16 & 0.755929 & 0.966092 \\
\hline Number of hospitalization days & 4.1 & 4.9 & -1.02224 & 0.318302 & 7 & 16 & 1.573592 & 1.768945 \\
\hline
\end{tabular}

umber of hospitalization days

4.1

$-1.02224$

0.318302

stools, fever, degree of dehydration, number of days of parenteral rehydration, and length of hospital stay. The average number of vomiting $24 \mathrm{~h}$ before admission in infants in the first group was $0.3 \pm 0.5$, in the second group was $4.6 \pm 3.3$, the difference was statistically significant $(p=0.002669)$. The average number of liquid stools in infants $24 \mathrm{~h}$ before admission in the first group was $3.7 \pm 0.8$, in the second group $10.4 \pm 4.9$, and the difference was statistically significant $(p=0.002152)$. Fever was reported in $14.3 \%$ of infants in the first group and in $81.25 \%$ in the second group, with statistically significant percentage difference $(p=0.0025)$. All infants from the first group had mild degree of dehydration, in the second group, a mild degree of dehydration was registered in $25.0 \%$, moderate in $43.75 \%$, and a severe degree of dehydration in $31.25 \%$ of infants. The average number of liquid stools during treatment in the first group was $9.0 \pm 2.2$, and in the second group was $21.2 \pm 8.5$, the difference between the average number of liquid stools was statistically significant $(p=0.001419)$. The average number of vomiting during treatment in the first group was $0.3 \pm 0.8$, and in the second group was 3.0 \pm 2.4 , the difference between the average number of vomiting was statistically significant $(p=0.008516)$. The average number of parenteral rehydration days in the first group was $0.7 \pm 0.8$, and in the second group, it was $2.0 \pm 1.0$, the difference between the average number of parenteral rehydration days was statistically significant $(p=0.005246)$. The average number of hospital days (length of stay) in the first group was $4.1 \pm 1.6$, and in the second group, it was $4.9 \pm 1.8$, the difference between the average number of hospital days was statistically insignificant for $p>0.05(p=0.318302)$.

Rotavirus was positive in 12 stool samples. In the first group, Rotavirus was positive in 1 (14.3\%) infant, and in the second group, Rotavirus was positive in $11(68.75 \%)$ infants. One infant from the second group was isolated Shigella flexneri and in one infant from the same group was isolated Adenovirus (Figure 1).

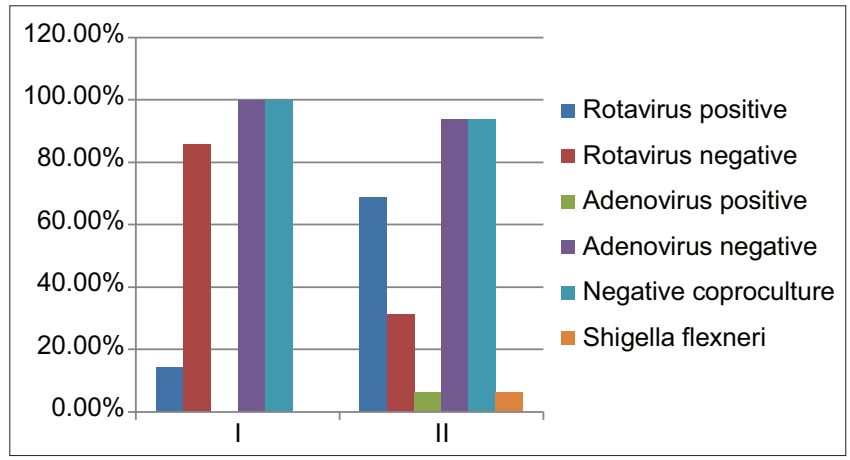

Figure 1: Microbiological findings in stool
The mean value of slgA in infants diagnosed with acute gastroenteritis in the first group was 3902.6 $\pm 1496.8 \mu \mathrm{g} / \mathrm{ml}$, and in the second group, it was 531.9 $\pm 506.2 \mu \mathrm{g} / \mathrm{ml}$, the difference between the mean values was statistically significant for $p<0.05$ ( $p=0.000000)$ (Figure 2).

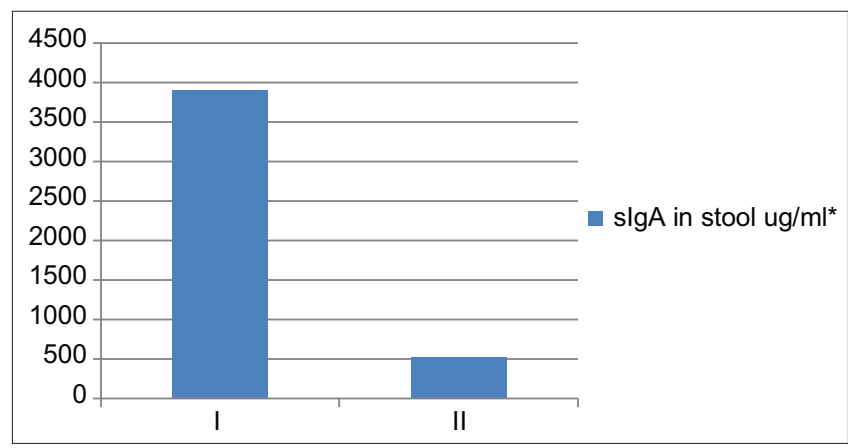

Figure 2: Average value of slgA in infants with acute gastroenteritis. slgA: Secretory immunoglobulin A. $t$-test $=8.198331 ; p=0.000000$ (statistically significant)

Table 3 shows the effect of sigA on the degree of dehydration, vomiting symptom, and fever in infants with acute gastroenteritis. We found a statistically significant association between dehydration rate, vomiting frequency, and fever between the first and second groups. Infants who were slgA positive had a significantly lower degree of dehydration, lower vomiting frequency, and fever.

Table 3: Effect of slgA on the clinical condition in infants with acute gastroenteritis

\begin{tabular}{llll}
\hline- & Negative slgA N=12 & Positive slgA N=11 & $\mathrm{p}$ \\
\hline Dehydration degree (\%) & & & $\mathrm{p}=0.004708$ \\
$\quad$ Mild & $2(16.6)$ & $9(81.8)$ & \\
$\quad$ Moderate & $5(41.7)$ & $2(18.2)$ & \\
$\quad$ Severe & $5(41.7)$ & 0 & $\mathrm{p}=0.036074$ \\
Fever (\%) & & & \\
$\quad$ No & $2(16.7)$ & $7(63.6)$ & \\
$\quad$ Yes & $10(83.3)$ & $4(36.4)$ & $\mathrm{p}=0.000383$ \\
Vomiting (\%) & $1(8.3)$ & $9(75.0)$ & \\
$\quad$ No & $11(91.7)$ & $2(25.0)$ & \\
$\quad$ Yes & &
\end{tabular}

A statistically significant association between exclusive breastfeeding and Rotavirus was registered for $p<0.05$ ( $p=0.016128)$. Exclusive breastfeeding is effective in preventing Rotavirus infection by reducing the risk of Rotavirus infection in infants, especially in the first 6 months of life, OR $=0.0758,95 \% \mathrm{Cl}(0.0071-0.8074)$.

\section{Discussion}

Several studies have confirmed that breastfed infants have significantly higher concentrations of slgA 
in the stool than those who have been formula fed, concluding that breast milk provides large amounts of slgA for infants and plays a major role in protection and promotion of the immune function of the infant's digestive tract [9], [10], [11], [12], [13]. The results of slgA in stool in infants with acute gastroenteritis from our research correlate with the results of the above studies. We observed a statistically significant association between group affiliation and the slgA levels in stool between the first and the second groups. Numerous studies have shown that slgA from breast milk has a protective effect against diarrhea in the first 6 months of life. Dialo et al., 2019 [14], noticed that breastfeeding discontinuation before the $3^{\text {rd }}$ month was found to be significantly associated with a high incidence of diarrhea at 6 months of age and between 6 and 12 months. Breastfeeding discontinuation (weaning) before the $6^{\text {th }}$ month was also associated with a higher incidence of diarrhea at 6 months of age. Infants who were on milk formula for $\geq 3$ months had a higher incidence of diarrhea between 6 and 12 months. Krawczyk et al., 2016 [15], and Plenge-Bönig et al., 2010 [16], have found that exclusive breastfeeding is effective in preventing Rotavirus infection by reducing the risk of Rotavirus infection in children, especially in the first 6 months of life. A few studies have shown that Rotavirus is a more common cause of acute gastroenteritis in infants than Adenovirus [17], [18]. These results support our findings that the most common cause of acute gastroenteritis in infants was Rotavirus. In the study by Sherif et al. 2015 [19] is shown that most of the breastfed infants with Rotavirus gastroenteritis had positive slgA values in stool as opposed to those infants who were on milk formula. Those infants who were positive for slgA in stool had a milder clinical picture and a lower frequency of vomiting. In our research, a statistically significant difference $(p=0.002669)$ for the average number of vomiting $24 \mathrm{~h}$ before admission was registered between the first and second groups with less frequent vomiting in exclusively breastfed infants in the first group, where slgA was positive in all stool samples. Regarding the number of liquid stools $24 \mathrm{~h}$ before admission to the hospital, a statistically significant difference was registered between the first and the second groups ( $p=0.002152$ ). Sherif et al., 2015 [19], did not prove statistical significance for the degree of dehydration between groups but in our study, the effect of slgA on the degree of dehydration in infants showed a statistically significant association between the first and second groups for $p=0.004708$. Similar results were obtained in the study of Fuchs et al., 1996 [20], which found that infants who were not breastfed were at higher risk of dehydration than those who were exclusively breastfed ( $p=0.006)$. In our study, vomiting during the treatment was less common in infants in the first group versus the second group with a statistically significant difference between the average number of vomiting by $p<0.05$. Regarding the average number of stools during the treatment, there was also a statistical significance for $p<0.05$ between the first and second groups. In the study of Eaton-Evans and Dugdale, 1987 [21] has been shown that breastfed infants up to 6 months of age have a lower number of liquid stools and a lower vomiting frequency compared to those who were fed with other types of milk, indicating that breast milk has a protective effect on the intestines of infants younger than 6 months. In our study, we observed statistical significance for the number of days of parenteral rehydration between the first and second groups. For the number of hospital days, no statistical significance was proved either between the first and the second groups. In contrast to our results in a study by Boccolini et al. 2012 [22] was shown that the increase in the prevalence of exclusive breastfeeding in infants younger than 4 months with acute diarrhea has a negative correlation with the duration of hospitalization (Rho $=-0.483, p=0.014)$. Our study has shown that exclusive breastfeeding is effective in preventing Rotavirus infection by reducing the risk of Rotavirus infection in children, especially in the first 6 months of life, OR $=0.0758,95 \% \mathrm{Cl}(0.0071-0.8074)$. This study had limitations because it was performed on a relatively small number of infants in a shorter follow-up period. During research of the published literature, we revealed a small number of studies examining the direct effect of breast milk slgA on the severity of the clinical picture in infants with acute gastroenteritis. For getting more significant evidence-based conclusions, more studies such as this one, higher number of participants and follow-up over a longer period of time are necessary. This would emphasize the importance of breastfeeding, especially in the first 2 years of life, because breast milk provides high concentrations of slgA that protects the intestinal epithelium of infants from damage in the presence of intestinal pathogens, as in this case protects, it from damage caused by Rotavirus acute gastroenteritis

\section{Conclusion}

In our study, we have shown that the presence of breast milk slgA in infants has an effect on the severity of the clinical signs of acute gastroenteritis by reducing the vomiting frequency, the number and severity of diarrheal episodes, the risk for moderate and severe dehydration, and fever frequency.

\section{References}

1. Guarino A, Ashkenazi S, Gendrel D, Lo Vecchio A, Shamir R, Szajewska H. Evidence-based guidelines for the management of acute gastroenteritis in children in Europe: Update 2014. J 
Pediatr Gastroenterol Nutr. 2014;59(1):132-52. https://doi. org/10.1097/mpg.0000000000000375

PMid:24739189

2. Mantis JN, Rol N, Corthésy B. Secretory IgA's complex roles in immunity and mucosal homeostasis in the gut. Mucosal Immunol. 2011;4(6):603-11. https://doi.org/10.1038/mi.2011.41 PMid:21975936

3. Boullier S, Tanguy M, Kadaoui KA, Caubet C, Sansonetti $P$, Corthesy $\mathrm{B}$, et al. Secretory IgA-mediated neutralization of Shigella flexneri prevents intestinal tissue destruction by downregulating inflammatory circuits. J Immunol. 2009;183(9):587985. https://doi.org/10.4049/jimmunol.0901838 PMid:19828639

4. Filipovic D. Humano mleko. In: Flipovic D, editor. Ishrana Zdrave I Bolesne Dece. Beograd: Nauka; 1995. p. 75-97.

5. Chirico G, Marzollo R, Cortinovis S, Fonte C, Gasparoni A. Antiinfective properties of human milk. JNutr. 2008;138(9):1801S6. https://doi.org/10.1093/jn/138.9.1801s PMid: 18716190

6. Newburg SD, Walker EA. Protection of the neonate by the innate immune system of developing gut and of human milk. Pediatr Res. 2007;61(1):2-8. https://doi.org/10.1203/01. pdr.0000250274.68571.18 PMid:17211132

7. Frank NM, Lynch KF, Uusitalo U, Yang J, Lönnrot M, Virtanen SM, et al, TEDDY Study Group. The relationship between breastfeeding and reported respiratory and gastrointestinal infection rates in young children. BMC Pediatr. 2019;19(1):339. https://doi.org/10.1186/s12887-019-1693-2

PMid:31533753

8. Santos FS, Santos FC, Santos LH, Leite AM, Mello DF. Breastfeeding and protection against diarrhea: An integrative review of literature. Einstein. 2015;13(3):435-40. https://doi. org/10.1590/s1679-45082015rw3107

PMid:26061078

9. Bridgman SL, Konya $T$, Azad MB, Sears MR, Becker AB, Turvey SE, et al. Infant gut immunity: A preliminary study of IgA associations with breastfeeding. J Dev Orig Health Dis. 2016;7(1):68-72. https://doi.org/10.1017/s2040174415007862 PMid:26690933

10. Maruyama K, Hida M, Kohgo T, Fukunaga $\mathrm{Y}$. Changes in salivary and fecal secretory $\lg A$ in infants under different feeding regimens. Pediatr Int. 2009;51(3):342-5. https://doi. org/10.1111/j.1442-200x.2008.02748.x PMid:19400812

11. Wang F, Shi C. Secretory immunoglobulin $A$ in human milk and infants' feces at 1-4 months after delivery. Zhonghua Fu Chan Ke Za Zhi. 1995;30(10):588-90.

PMid:8745502

12. Koutras AK, Vigorita VJ. Fecal secretory immunoglobulin $a$ in breast milk versus formula feeding in early infancy. $J$ Pediatr Gastroenterol Nutr. 1989;9(1):58-61. https://doi. org/10.1097/00005176-198907000-00011

\section{PMid:2778570}

13. McLean B, Holmes IH. Transfer of antirotaviral antibodies from mothers to their infants. J Clin Microbiol. 1980;12(3):320-5. https://doi.org/10.1128/jcm.12.3.320-325.1980 PMid:6260832

14. Diallo AF, McGlothen-Bell K, Lucas R, Walsh S, Allen C, Henderson WA, et al. Feeding modes, duration, and diarrhea in infancy: Continued evidence of the protective effects of breastfeeding. Public Health Nurs. 2019;37(2):155-60. https:// doi.org/10.1111/phn.12683

PMid:31709650

15. Krawczyk A, Lewis MG, Venkatesh BT, Nair SN. Effect of exclusive breastfeeding on rotavirus infection among children. Indian J Pediatr. 2016;83(3):220-5. https://doi.org/10.1007/ s12098-015-1854-8 PMid:26307755

16. Plenge-Bönig A, Soto-Ramírez N, Karmaus W, Petersen G, Davis S, Forster J. Breastfeeding protects against acute gastroenteritis due to rotavirus in infants. Eur $\mathrm{J}$ Pediatr. 2010;169(12):1471-6. https://doi.org/10.1007/ s00431-010-1245-0

PMid:20617343

17. Al-Ali RM, Chehadeh W, Hamze M, Dabboussi F, Sani H, Hassan M. First description of gastroenteritis viruses in Lebanese children: A pilot study. J Infect Public Health. 2001;4(2):59-64. https://doi.org/10.1016/j.jiph.2011.01.002 PMid:21663874

18. Carraturo A, Catalani V, Tega L. Microbiological and epidemiological aspects of Rotavirus and enteric adenovirus infections in hospitalized children in Italy. New Microbiol. 2008;31:329-36

PMid: 18843886

19. Sherif LS, Raouf RK, EI Sayede RM, EI Wakkadd AS, Shoaib AR, Ali $\mathrm{HM}$, et al. Glutathione transferase as a potential marker for gut epithelial injury versus the protective role of breast milk slgA in infants with rota virus gastroenteritis. Open Access Maced J Med Sci. 2015;3(4):676-80. https://doi.org/10.3889/ oamjms.2015.125

PMid:27275307

20. Fuchs SC, Victora CG, Martines J. Case-control study of risk of dehydrating diarrhoea in infants in vulnerable period after full weaning. BMJ. 1996;313(7054):391-4. https://doi.org/10.1136/ bmj.313.7054.391

\section{PMid:8761225}

21. Eaton-Evans J, Dugdale AE. Effects of feeding and social factors on diarrhea and vomiting in infants. Arch Dis Child. 1987;62(5):445-8. https://doi.org/10.1136/adc.62.5.445 PMid:3606175

22. Boccolini CS, Boccolini Pde M, de Carvalho ML, de Oliveira MI Exclusive breastfeeding and diarrhea hospitalization patterns between 1999 and 2008 in Brazilian state capitals. Cien Saude Colect. 2012;17(7):1857-63. https://doi.org/10.1097/01. ede.0000417133.40700.69

PMid:22872348 